cators of the need for health care (p 1046). ${ }^{7}$ Statistical models of small area variations in use of hospital resources were developed in an attempt to distinguish between "legitimate" needs such as health status and deprivation and "illegitimate" influences such as the availability of hospital beds, general practitioners, and nursing homes.

In the second article Smith et al outline the main results of the analyses and show their possible impact at the level of the former regional health authorities (p 1050). ${ }^{8}$ Their four key findings are that the present method of weighted capitation overstates the costs of providing health care to elderly people; socioeconomic characteristics of areas are important determinants of the use of health care in addition to conventional indicators of health status such as mortality; small area indicators of need vary between different services such as acute and psychiatric specialties; and the availability of non-hospital resources has an important bearing on the demand for hospital care. The overall effect of taking these findings into account would be to redistribute resources to relatively deprived inner city areas at the expense of more affluent parts of the country.

The final article, by Sheldon et al, describes an attempt to use routinely collected data about hospital use to identify population based indicators of need that improve the setting of budgets for general practice fundholders (p 1059).9 Despite using the most advanced statistical techniques the authors fail to find any convincing evidence that factors of need other than the age and sex structures of the local population are associated with small area variations in the use of hospital resources. They conclude with some justification that further research is needed to establish a resource allocation formula that is sensitive to variations in the costs of treatment. In the meantime continued vigilance will be required to ensure that incentives for general practitioners to exclude potentially expensive patients are not inadvertently created by any new method of allocating resources to fundholders.

Despite, or even perhaps because of, their complexity the analyses presented in these papers represent a major advance in assessing the relative health care needs of small areas. They respond as far as possible to many of the common criticisms of previous attempts to develop empirically based resource allocation formulas. Nevertheless, some problems remain that are mainly due to inadequacies in the data available for analysis. One deficiency has been the lack of a consistent method of costing episodes of hospital use across specialties. Another is that the indicators used to measure access to health care and the need for treatment are highly correlated with each other, and this hugely complicates the statistical modelling. For example, whether the "illegitimate" influences of supply on observed patterns of hospital use have been, or indeed could ever be, fully taken into account remains debatable.

A wider set of questions exists about the practical interpretation of the findings that relate to the narrow terms of reference within which the analysts had to work rather than the quality of their work itself. For example, although the review of weighted capitation was confined to the hospital and community health services, one may clearly infer from the papers that it is a serious mistake to evaluate relative needs for hospital services in isolation of an assessment of similar requirements for primary and community based care. A more comprehensive approach to establishing the relative health and social needs of different areas that transcends arbitrary service and administrative boundaries is now required. The latest research reported in this week's journal highlights the illogicality of, for example, allocating money to purchasers in London to buy hospital services without taking account of the relative lack of facilities for continuing care in the capital.

KEN JUDGE Director

NICHOLAS MAYS

King's Fund Institute,

London W2 4HT

1 Department of Health and Social Security. Sharing resources for health in England: report of the Resource Allocation Working Party. London: HMSO, 1976.

2 Royston GDH, Hurst JW, Lister EG, Stewart PA. Modelling the use of health services by populations of small areas to inform the allocation of central resources to larger regions. Socio-Econ Planning Sci 1992;26:169-80.

3 Carstairs V. Health care needs, deprivation, and the resource allocation formula. In: Gilman E, et al, eds. Resource allocation and health needs: from research to policy. London: HMSO, 1994: 5-18.

4 Mays N. NHS resource allocation after the 1989 white paper: a critique of the research for the RAWP review. Community Medicine 1989;11:173-86.

Sheldon TA, Davey Smith G, Bevan G. Weighting in the dark: resource allocation in the new NHS. BMY 1993;306:835-9.

6 Judge K, Mays N. Allocating resources for health and social care in England. BMF ; 308:1363-6.

7 Carr-Hill RA, Sheldon TA, Smith P, Martin S, Peacock S, Hardman G. Allocating resources to health authorities: development of method for small area analysis of use of inpatient services. BMF 1994;309:1046-9.

8 Smith P, Sheldon TA, Carr-Hill RA, Martin S, Peacock S, Hardman G. Allocating resources to health authorities: results and policy implications of small area analysis of use of inpatient services. $B M F$ 1994;309:1050-4.

9 Sheldon TA, Smith P, Borwitz M, Martin S, Carr-Hill R. Attempt at deriving a formula for setting general practitioner fundholding budgets. BMf 1994;309:1059-64.

\title{
The future of purchasing
}

\section{Tolerance of diversity will be necessary}

At last week's Conservative party conference the government's plans for the future of fundholding were unveiled. ${ }^{1}$ To understand the significance of these it is important to remember the history of purchasing so far. Working for Patients established two models of purchasing, one centred on health authorities and the other on general practitioners. Health authorities approach purchasing from a population perspective and bring to bear a range of skills in public health and other disciplines to assess health care needs. On the basis of needs assessment, health authorities buy the full range of care for their population except for those services under the control of fundholders. Fundholders are responsible for purchasing a limited list of services and do so in a way that is responsive to patients' demands. There is therefore a contrast between needs based purchasing by health authorities and demand led purchasing by fundholders.

In practice, health authorities and general practitioners in different parts of the NHS have developed a range of approaches to purchasing, which seek to combine the leverage of health authorities with the bite of fundholders. ${ }^{2}$ These include general practitioners giving advice to health authorities, locality purchasing, practice sensitive purchasing, fundholding consortiums, general practitioner multifunds, and total fundholding. All these initiatives have emerged spontaneously as policy has been driven from the bottom up rather than the top down. One of the consequences has been competition among purchasers as those involved in different approaches seek to show that they are best placed to achieve improved services. 
While competition among purchasers has served as a powerful stimulus for change, it has resulted in a risk of fragmentation in the absence of any formal mechanism for coordinating the plans of health authorities with those of fundholders. With fundholding limited to a small proportion of general practitioners, this did not matter much, but the expansion of fundholding meant that a review could not be delayed. Not least there was a danger of duplication as the emergence of integrated purchasing between health authorities and general practitioners ran in parallel with fundholding in its various guises.

The outcome of that review provides the basis for the next stage in the development of purchasing. The new arrangements emphasise purchasing led by primary care and centered on fundholding. This entails three levels of fundholding: an expanded version of the existing scheme for practices with 5000 patients or more; experiments in total purchasing at around 20 sites for groups of practices serving populations of over 30000 ; and an option of community fundholding for small practices with 3000 patients or more to purchase staff, drugs, and community health services. The principal aim is to encourage more general practitioners to become fundholders and to enable a wider range of services to be purchased at the practice level. Although no official targets have been set, the Department of Health expects that the proportion of the population covered by fundholders will double by 1997-8. Ministers hope that fundholding will be so firmly embedded by the next election that it will be impossible to reverse.

Where does this leave health authorities? Under the government's plans, district health authorities and family health services authorities will merge to form unified health authorities in April 1996, subject to parliament approving legislation that is currently being drafted. The intention is that the new health authorities will participate in developing local health strategies with general practitioners and others, regulating the performance of practices and the operation of fundholding, and supporting general practitioners as both purchasers and providers. This means that they will be less directly involved in purchasing than at present and will therefore be able to place greater emphasis on strategic commissioning. Implicit in these arrangements is the assumption that fundholders will be held to account for their performance by health authorities. It is this that opens up the possibility of a more coherent approach to purchasing being developed. Increased power implies greater responsibility, and fundholders are likely to find that the control they have been given over resources has been achieved at the price of appreciably enhanced accountability.

Several issues arise from the government's plans. To begin with, the expansion of fundholding adds urgency to the task of finding a way of allocating budgets to health authorities and fundholders that ensures equity. The present system, in which health authorities are funded through a capitation formula and fundholders' budgets are based on historic activity, has been criticised as favouring general practitioners and producing unfairness in the allocation of resources. The logical solution to this problem is to apply the same formula to different types of purchasers, but this has to be done in a way that avoids general practitioners discriminating against expensive patients. Arrangements will also have to be put in place for general practi-tioners to share risks so that they cope with the cost of patients whose conditions could give rise to overspending. ${ }^{3}$

A further concern is that transaction costs are likely to increase. These arise partly from the management allowances paid to fundholders but, more importantly, result from the additional workload for providers in negotiating contracts with many small purchasers. The supporters of fundholding argue that the transaction costs are more than outweighed by the improvements in efficiency that have been achieved. While there is some support for this from research into the impact of fundholding, ${ }^{3}$ the fact is that the policy of controlling management costs cannot be applied selectively. Fundholding must be included in this policy, particularly when schemes in which general practitioners collaborate with health authorities in purchasing seem more economical to run.

Another issue is general practitioners' willingness to participate in the proposed arrangements. The workload entailed in fundholding and the increasing responsiveness of many health authority purchasers to general practitioners, not to mention strongly held political and ethical objections, may mean that many general practitioners will prefer to influence purchasing in ways other than by becoming fundholders, provided that they have this choice. There is increasing experience within the NHS of effective integrated purchasing between health authorities and general practitioners ${ }^{56}$ - the approach favoured by the Labour party-and it is an open question whether this approach or fundholding will prove the more durable.

\section{Are all GPs up to the task?}

A related issue is the organisational capacity within general practice to take on a bigger role in purchasing. The reality is that the general practitioners who advise politicians are not always typical of their colleagues. Although great strides have been made in improving primary care services, standards remain variable. This should not deter well organised practices from assuming greater responsibility for the care of patients, but it casts doubt on the ability of general practice as a whole to perform the func-tions envisaged by ministers. Unless a major effort is made to tackle this issue the vision of an NHS in which purchasing is truly led by primary care will remain unfulfilled.

All of this suggests that reports of the death of health authorities may be premature. The reality is that purchasing will continue to develop in various ways, and no single model is likely to prevail. If the government's plans enable the strategic approach of health authorities to be combined with the responsiveness of general practitioners in a way that is sensitive to different local circumstances there is a chance of extracting the best of the original models of pur-chasing set out in Working for Patients. The key is tolerance of diversity of purchasing within an agreed framework.

CHRIS HAM Director

Health Services Management Centre,

University of Birmingham,

Birmingham B15 2RT

The Health Services Management Centre is a self financing unit within the University of Birmingham and its work is supported by a range of organisations including the Department of Health, health authorities, and other funding bodies.

1 Beecham L. Tories extend general practice fundholding. BMf 1994;309:1039. 2 Shapiro J. Shared purchasing and collaborative commissioning with the NHS. Birmingham National Association of Health Authorities and Trusts, 1994.

3 Judge K, Mays N. A new approach to weighted capitation. BM7 1994;309:895-6.

4 Glennerster H, Matsaganis M, Owens P, Hancock, S. Implementing GP fundholding. Glennerster H, Matsaganis M, Owens P,
Buckingham: Open University Press, 1994.

5 Black DG, Burchall AD, Trimble IMG. Non-fundholding in Nottingham: a vision of the future. $B M \mathcal{F}$ 1994;309:930-2.

6 Ham C, Willis A. Think globally act locally. Health Service fournal 1994; 104:27-8. 